\title{
Research on the Formation Mechanism of Loess Vertical Joints
}

\author{
Chenxing Wang $\mathbb{D},{ }^{1}$ Ruijun Jiang $\mathbb{D},{ }^{1}$ Hong Wang $\mathbb{D}^{2},{ }^{2}$ Tonglu Li $\mathbb{D},{ }^{1}$ Haiwei Kang $\mathbb{D},{ }^{1}$ \\ and Xiaokun Hou ${ }^{3}{ }^{3}$ \\ ${ }^{1}$ Department of Geological Engineering, Chang'an University, Xi'an, Shaanxi 710054, China \\ ${ }^{2}$ Coal Geological Geophysical Exploration Surveying \& Mapping Institute of Shanxi Province, Taiyuan 030600, China \\ ${ }^{3}$ Key Laboratory of Shale Gas and Geoengineering, Institute of Geology and Geophysics, Innovation Academy for Earth Science, \\ Beijing 100029, China
}

Correspondence should be addressed to Ruijun Jiang; 2018026025@chd.edu.cn

Received 2 December 2020; Revised 6 January 2021; Accepted 28 January 2021; Published 10 February 2021

Academic Editor: Song-He Wang

Copyright (c) 2021 Chenxing Wang et al. This is an open access article distributed under the Creative Commons Attribution License, which permits unrestricted use, distribution, and reproduction in any medium, provided the original work is properly cited.

\begin{abstract}
The popular occurrence of vertical joints in loess formation aggravates the anisotropism of loess and contributes to various geohazards (e.g., slope failures and soil erosion). To alleviate the geohazards caused by the vertical joints, researches need to be carried out to investigate the formation mechanism of these vertical joints. However, the theoretical analysis of the vertical joints' formation mechanism is limited up to now. In this study, we conducted a laboratory column experiment to observe joint development. Furthermore, using the unsaturated soil theory, we proposed a theoretical model to investigate the tensile stress that contributes to the formation of the loess vertical joint. In the experiment, the air-dried and crushed soil was sifted into the column, which simulates the free fall deposition process of the natural loess in China and contributes to a uniform state. $2500 \mathrm{ml}$ of water was added at the top of the column. The topsoil experienced a wetting-drying process. During desaturation, 9 similar vertical joints were developed with similar horizontal distance. A theoretical model that calculates the interparticle force or tensile force between two adjacent particles was proposed based on the force balance equations. The theoretical model elucidates the phenomena in a laboratory experiment well and provides an insight into the formation mechanism of vertical joints in a uniform soil. The results highlight the generation of vertical joints in the initial deposition stage of loess with a uniform particle arrangement. Besides, the tensile force that contributes to the joint formation arises from the matric suction and surface tension of the solid-water-air contractile film.
\end{abstract}

\section{Introduction}

The loess plateau of China has the most widely distributed $\left(6.4 \times 10^{4} \mathrm{~km}^{2}\right)$ and thickest (e.g., $\left.200 \mathrm{~m}\right)$ loess deposits in the world. The loess transported by wind from the Gobi desert deposits mainly in the north-west region (Figure 1). The aeolian depositing loess forms with a metastable structure that is sensitive to water. When the loess is subjected to water, the stiffness and strength markedly decrease, leading to various disasters (e.g., landslides, collapse deformation, and differential settlement) [1-6]. The most common geohazard is landslide [7]. Li et al. [8] proposed a unified landslide classification system for loess slopes based on the possible mechanisms underlying each class of failure. The failure of loess slopes is typically associated with the loess joint and water. It is well acknowledged that water is the dominant factor that induces various geological hazards in the loess plateau of China $[2,5,9,10]$. Extensive studies have been carried out to investigate the hydromechanical properties of loess with various water contents [11-13] and water migration characteristics in the thick loess layer [2, 14-17]. However, the loess vertical joint has not received enough attention that it deserves [18].

Loess vertical joints are weak structural planes in the intact loess that developed during the loess formation $[8,18,19]$. Figure 2 illustrates a typical vertical joint developed in the late Pleistocene during loess deposition. The joint cuts the loess into columns that are prone to fail when 


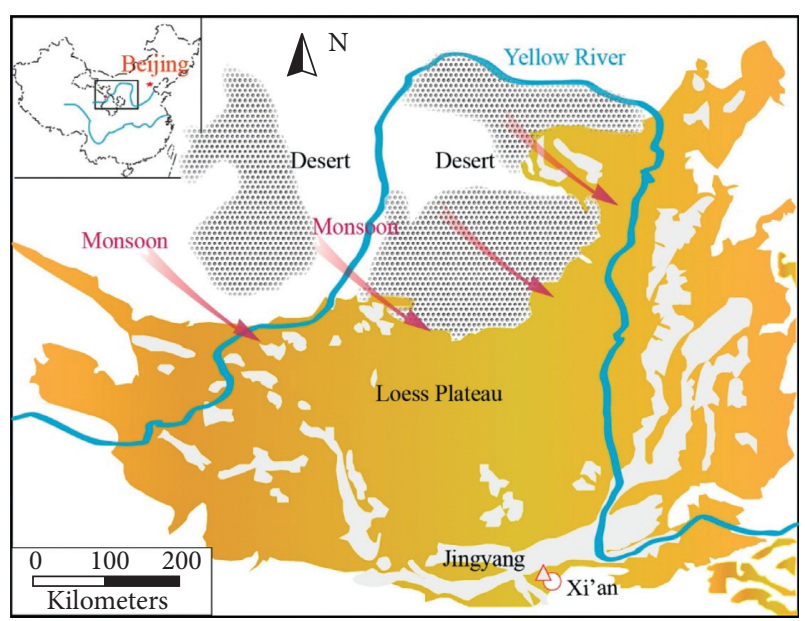

Figure 1: Loess area of China (adapted from Hou et al. [14]).

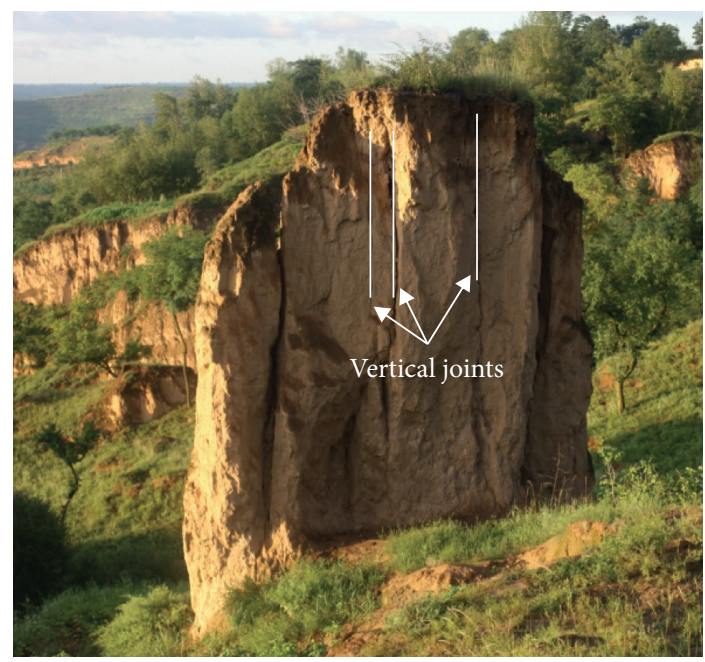

Figure 2: Typical vertical joints developed in late Pleistocene.

the foot is wetted. Furthermore, the vertical joint is the preferential flow path of ground surface water (e.g., precipitation and irrigation water). The surface water contributes to the marked variation of the hydraulic condition of a hillslope and further failure of the slope $[17,20,21]$. Besides, during rainfall, extensive erosion occurs along the vertical joints [22]. Figure 3 shows typical erosive holes at the top of the loess highland.

Available studies attribute the formation of vertical joints to differential collapse deformation [23], tension force $[23,24]$, privilege pore characteristics (e.g., pore concentration zone and vertical tubular channel) [8], and biological activities [25]. Luo et al. [23] used remolded soils composed of several soil layers with different heights. After the inundation of the specimen, joints appeared at the points where the layer thickness was changeable and differential collapsibility happened. The joints expanded in the vertical direction. Therefore, Luo et al. [23] believe that uneven collapsibility is the reason for the development of vertical joints. However, field observation suggests that vertical

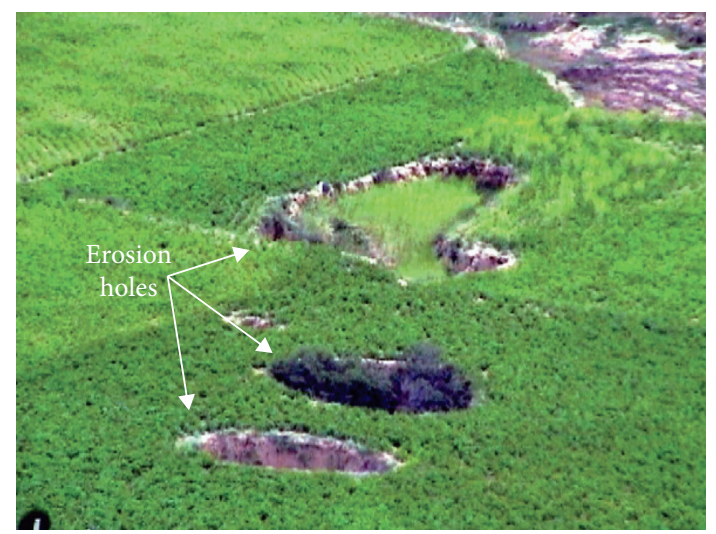

Figure 3: Erosive holes on the top of the loess highland.

joints also develop at the place where the loess beds are completely uniform without uneven collapsibility. Wang et al. [24] considered that horizontal tensile stress at the edge of the large pores in loess is the fundamental factor to generate vertical joints. The tensile stress is created by the overburden pressure. However, for the aeolian deposit, the horizontal stress caused by overburden is typically compression stress other than tension stress under the confined condition. Li et al. [8] believed that the privilege pore zone and vertical tubular channel in loess are the micromesoscopic structural basis for the development of vertical joints. However, the analysis in this study is descriptive without theoretical or quantitative investigation. Some other scholars [26] held the idea that structural characteristics, horizontal tension, and weathering were the major reasons for vertical joints' formation in loess. However, most of these studies are qualitive analysis. Theoretical studies of vertical joints' formation mechanism are rather limited in the literature.

The objective of this study is to reveal the formation mechanism of the vertical joint. A column model experiment was conducted. Air-dried and crushed loess particles were sifted into the column, which simulated the natural deposition process of in situ loess. Afterward, the soil was subjected to water and vertical joints appeared at the top of the column. A theoretical model was established to quantitatively investigate the formation mechanism of the vertical joints. The experimental and theoretical investigation of this study reinforces our understanding of the formation mechanism of the loess vertical joint.

\section{Materials and Methods}

2.1. Soil Samples and Tests. The soil samples were collected from the southern edge of the Loess Plateau in Jingyang county near Xi'an city, China (Figure 1). The basic physical properties of the sample are shown in Table 1. The soil grain size distribution curve and cumulative distribution curve obtained by a Bettersize 2000 laser grain size analyzer are presented in Figure 4. Based on the data in Table 1 and Figure 2, the soil can be classified as clay of low plasticity (CL) according to the Unified Soil Classification System (USCS : ASTM 2011). Parameter $d_{50}$ is the particle diameter 
TABLE 1: Physical properties of soils used in this study.

\begin{tabular}{lc}
\hline Parameter & Value \\
\hline Specific gravity $G_{\mathrm{s}}$ & 2.69 \\
Liquid limit $w_{\mathrm{l}}(\%)$ & 30.2 \\
Plastic limit $w_{\mathrm{p}}(\%)$ & 19.8 \\
Plastic index $I_{\mathrm{p}}$ & 10.4 \\
Initial water content $(\%)$ & 2.6 \\
Sand content $(2-0.075 \mathrm{~mm})(\%)$ & 0.7 \\
Silt content $(0.075-0.002 \mathrm{~mm})(\%)$ & 84.9 \\
Clay content $(\leq 0.002 \mathrm{~mm})(\%)$ & 14.4 \\
\hline
\end{tabular}

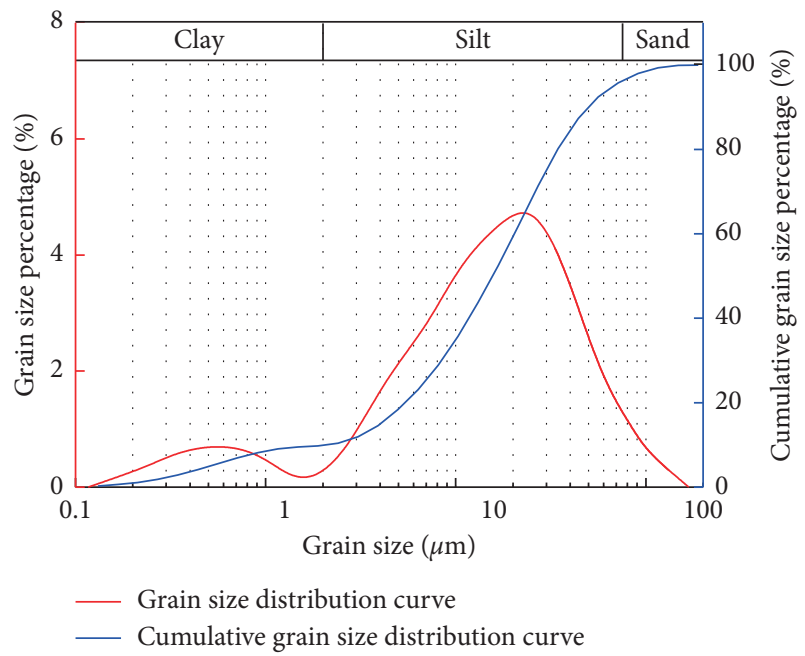

Figure 4: Grain size distributions of the tested soil.

below which the mass of particles takes account of $50 \% . d_{50}$ is regarded as a measurement of the intensity of winter monsoon winds that are responsible for dust transportation [27]. $d_{50}$ of this tested soil is $15.1 \mu \mathrm{m}$.

2.2. Laboratory Model Experiment. The laboratory model experiment was conducted in a plexiglass cylinder shown in Figure 5(a). Its height was $200 \mathrm{~cm}$. The inner and outer diameters were $23.6 \mathrm{~cm}$ and $25 \mathrm{~cm}$, respectively. The soil prepared for the model experiment was air-dried and crushed into powder with grinding rubber. The water content of air-dried soil is $2.6 \%$. The soil powder was sifted into the cylinder via a $0.5 \mathrm{~mm}$ sieve continuously to simulate the natural deposition process of loess. When the specimen achieved the required height (i.e., $180 \mathrm{~cm}$ height), the total mass was $91.1 \mathrm{~kg}$. Under this self-weight compaction state (or initial state), the soil has a void ratio $e_{0}$ of 1.650 and a dry density of $1.02 \mathrm{~g} / \mathrm{cm}^{3}$. Then the static loading of $30 \mathrm{~kg}$ (i.e., $6.7 \mathrm{kPa}$ ) was loaded on the top to compact the soils. The soil height was stable at $1780 \mathrm{~mm}$ within 3 days. The density and dry density of soils after loading were $1.17 \mathrm{~g} / \mathrm{cm}^{3}$ and $1.14 \mathrm{~g} /$ $\mathrm{cm}^{3}$, respectively. The void ratio $e_{1}$ after loading was 1.360 . This condition was defined as the weak compaction state. A layer of fine sand with a thickness of $100 \mathrm{~mm}$ that functions like a porous stone was evenly placed on the top of the column. This layer of sand was to prevent concentrated infiltration along the sidewall and to facilitate uniform

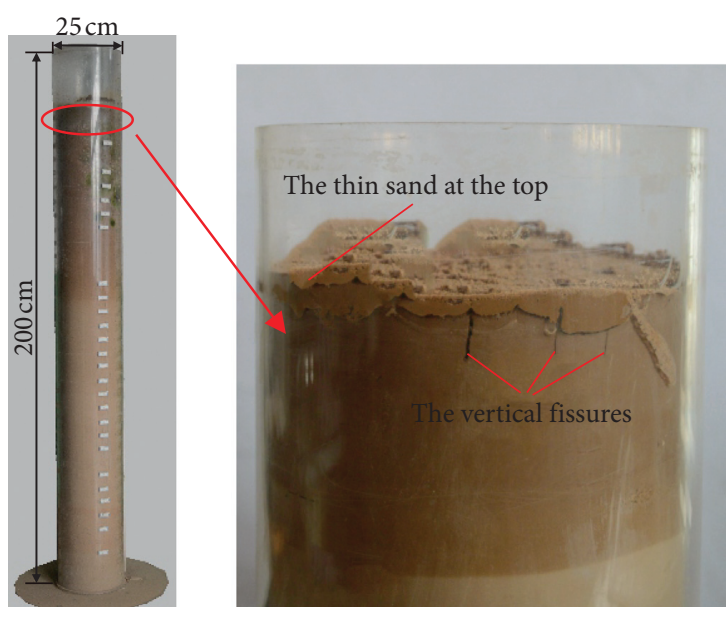

(a)

(b)

Figure 5: (a) The model experiment and (b) fissure phenomena after water penetration.

infiltration at the top surface of the sample. The saturated permeability coefficient of the weak compaction state sample was $6.42 \times 10^{-4} \mathrm{~m} / \mathrm{s}$, measured by TST- 55 permeameter.

Water was added on top of the column by a spray, which simulates the natural rainfall. The spraying process lasted for 30 minutes and the total volume of water added was $2500 \mathrm{ml}$. The saturated zone appeared on the top for a short period. Then water moved downwards along with a decrease of the soil-water content for the top saturated soil. One hour later, nine vertical cracks with roughly equal distance formed, as shown in Figure 3(b). The fact that the crack is the initial form of the loess joint should be noted. We measured the water content (i.e., $31.5 \%$ ) of soil where the crack developed. The total settlement of the soil column was $50 \mathrm{~mm}$. This state was defined as the postinfiltration state. The soil void ratio $e_{2}$ at this state reduced to 1.100 . The vertical crack did not develop either horizontally or vertically in the following 24 hours during which the soil at the top underwent a drying process. The length and width of the cracks were listed in Table 2.

2.3. Theoretical Model. The laboratory model experiment showed that the formation of vertical joints in loess was highly related to water. To analyze the role of water in the vertical joints formation, an idealized model was proposed. In this model, the interparticle force is mainly composed of matric suction and surface tension, ignoring the change of internal force of soil particles caused by air pressure. Meanwhile, soil particles were considered as uniform spheres with the same diameters [28]. These soil grains were arranged evenly as shown in Figure 6, regardless of the fine particle clustering between the coarse grains. Using the average particle diameter of the sample $d_{50}$ as the grain size, the average volume of a single soil particle is

$$
V_{P}=\frac{1}{6} \pi d_{50}^{3}
$$

For a cube model whose edge is $l \mu \mathrm{m}$ as a unit, the volume is 
TABle 2: The vertical joints in the model experiment.

\begin{tabular}{lcc}
\hline Number & Length $(\mathrm{cm})$ & Width $(\mathrm{mm})$ \\
\hline 1 & 10.3 & 3.2 \\
2 & 10.3 & 3.3 \\
3 & 8.0 & 2.3 \\
4 & 9.0 & 2.4 \\
5 & 8.0 & 2.5 \\
6 & 9.5 & 3.5 \\
7 & 6.0 & 3.3 \\
8 & 9.0 & 3.2 \\
9 & 5.0 & 3.2 \\
\hline
\end{tabular}

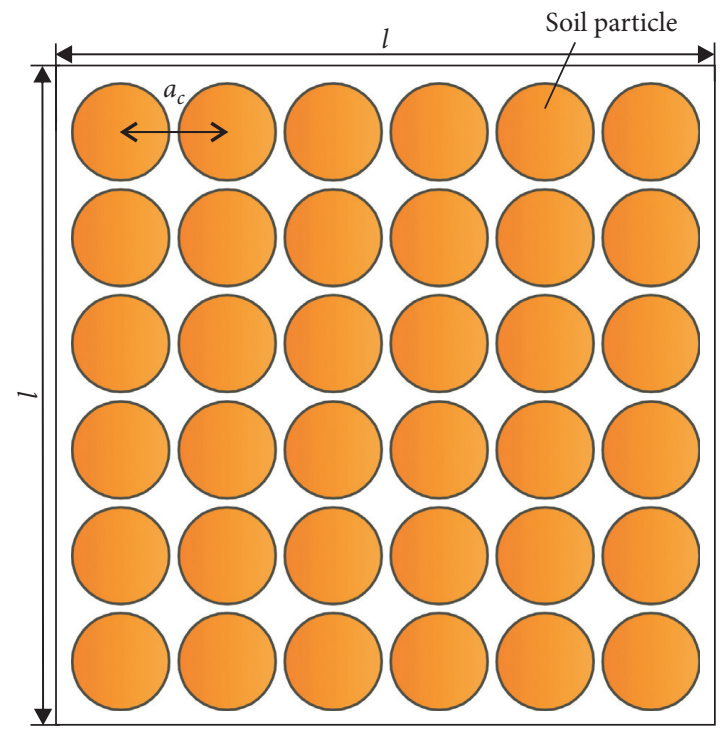

Figure 6: The cross section of soil particles arrangement.

$$
V=l^{3}
$$

The volume of the solid particles in the cube model is

$$
V_{S}=\frac{V}{1+e}
$$

where $e$ is the void ratio of soil. The number of soil particles is

$$
N=\frac{V_{S}}{V_{P}}
$$

Assuming that the center of soil particles arranged following the shape of the cube model, the grain number along the side of the cube model is

$$
n=\sqrt[3]{N}
$$

The distance $a_{c}$ between the centers of two particles is

$$
a_{c}=\frac{l}{n}
$$

$a_{c}$ also can be derived by placing formula (1)-formula (5) into formula (6) as follows:

$$
a_{c}=d_{50} \sqrt[3]{\frac{\pi(1+e)}{6}} .
$$

The soil particle arrangement of the horizontal cross section at any void ratio is shown in Figure 6. If $a_{c}$ is equal to $d_{50}$, the distance between two particles will be 0 , which means the soil particles contact each other. This state is defined as the dense arrangement state. In this state, the void ratio $e_{3}$ is 0.91 theoretically [28].

When the soil is partially saturated, the air-water-soil interface forms between the two particles. The geometric relationship is illustrated in Figure 7:

$$
\begin{aligned}
& r_{1}=\frac{a}{\cos \theta}-R, \\
& r_{2}=a \tan \theta-r_{1},
\end{aligned}
$$

where $r_{1}$ is the radius of the contractile skin; $r_{2}$ is the center radius of the capillary water column; $R$ is the radius of the ideal soil particle; $a$ is half of the center spacing between soil particles; $\theta$ is the filling angle.

For monosized particles, a free-body diagram for the relevant system forces that involves a contribution from air pressure, pore water pressure, surface tension, and applied external force or overburden pressure is shown in Figure 8.

The resultant interparticle force is

$$
P_{s}=\left(u_{a}-u_{w}\right) \pi r_{2}^{2}+T_{s}\left(2 \pi r_{2}\right)
$$

where $u_{a}$ is air pressure; $u_{w}$ is pore water pressure; $u_{a}-u_{w}$ is the matric suction and $T_{s}$ is surface tension, which is $72.0 \mathrm{mN} / \mathrm{m}$ at $25^{\circ} \mathrm{C}$.

From equation (10), it can be seen that the interparticle force is related to the matric suction, surface tension, and soil-water content (i.e., $r_{2}$ ). The relationship between matric suction and surface tension in unsaturated soil can be expressed using the Laplace [29]

$$
u_{a}-u_{w}=T_{s}\left(\frac{1}{r_{1}}-\frac{1}{r_{2}}\right) \text {. }
$$

Substituting equations (8) and (9) into (11), the matric suction is

$$
u_{a}-u_{w}=\frac{T_{S} \cos \theta(a \sin \theta+2 R \cos \theta-2 a)}{(a-R \cos \theta)(a \sin \theta+R \cos \theta-a)} .
$$

Therefore, with a given particle spacing (i.e., $a$ ), a specific filling angle $\theta$ corresponding to a certain value of matric suction can be calculated using equation (12). By substituting the filling angle into equations (8) and (9), $r_{1}$ and $r_{2}$ can be obtained. Eventually, the interparticle force can be calculated from equation (10).

\section{Analysis and Results}

Theoretical analysis is conducted with three series of parameters using the theoretical model established above. The 


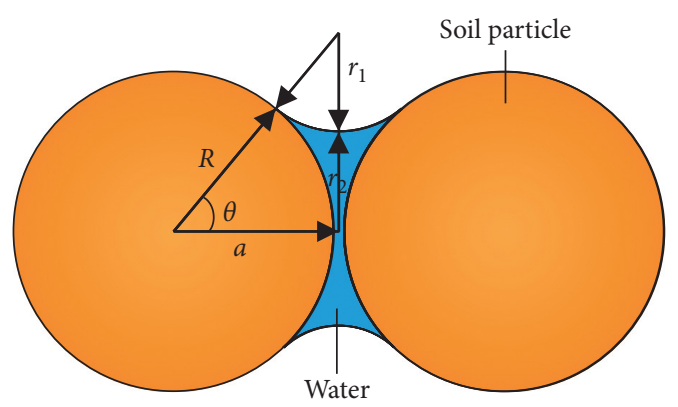

FIgURE 7: Toroidal geometry of the air-water-solid interface.

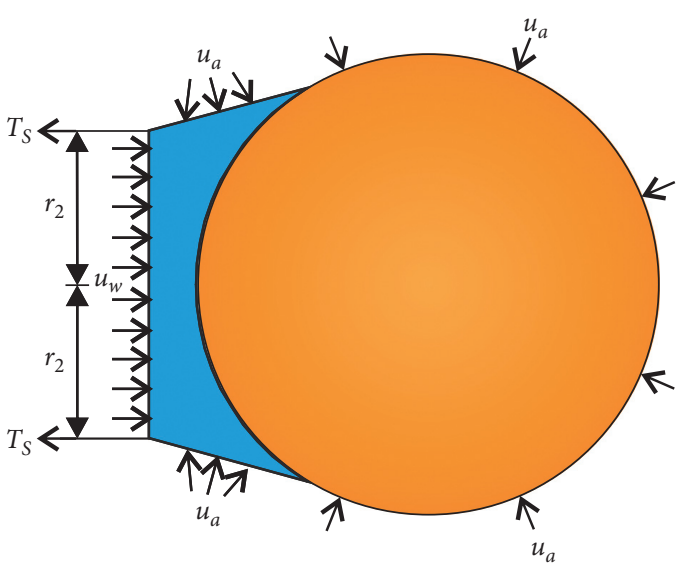

FIGURE 8: Free-body diagram of inter-particle forces.

three series correspond to the three different states in the laboratory experiment, namely, the initial state, weak compaction state, and postinfiltration state. The physical parameters (i.e., water content, dry density, and void ratio) corresponding to the three states have been obtained during the experiment and are used in this section. The particle size is $15.1 \mu \mathrm{m}$, which equals $d_{50}$ of the tested soil in the laboratory experiment. In the experiment, the soil at the top of the soil column experiences a wetting-drying process following four stages that are shown in Figure 9. In the beginning, there is no water in the pores. The space among soil particles is filled with air (Figure 9(a)). In such a scenario, there are neither contractile films nor surface tension acting on the soil particles. After infiltration, the surface soil is saturated, and the pores between particles are filled with water (Figure 9(b)). In this state, matric suction is zero. In addition, there is no surface tension acting on the soil particles. When the water propagates downward after we stop adding water from the top, air enters the pore and is surrounded by free water (Figure 9(c)). In such a scenario, the air-water surface tension does not act on the soil particles. However, the matric suction is not zero and tends to pull the adjacent particles together. With downward propagation of the water, the water content of the soil at the top of the column decreases with the discharged water space occupied by the air. Then the water-air-solid interface develops (Figure 9(d)) and the contractile film plays an important role in pulling the adjacent soil particles together.

According to equation (7), interparticle space $a_{\mathrm{c}}$ is only related to void ratio $e$ as $d_{50}$ is constant. The parameters of soil at different states (i.e., initial deposition state, weak compaction state, and postinfiltration state) in the laboratory experiment process are shown in Table 3. The parameters at the dense arrangement state, which assumes that $a_{\mathrm{c}}$ equals $d_{50}$, are also shown in Table 3 .

The data in Table 3 shows that the soil pores are continuously compressed and the void ratio reduces gradually as the soil state changes from the initial deposition state to the dense arrangement state. The position of soil particles changes and the shrinkable space between particles decreases. Based on equation (10), the relationship between matric suction and interparticle force at different states can be obtained (Figure 10).

If the soil is approximately saturated or matric suction is close to zero (i.e., $1 \mathrm{kPa}$ in Figure 10), the interparticle force increases with the decrease of the particle distance or void ratio. Along with the increase of matric suction, the interparticle force decreases gradually or keeps constant at the beginning and then drops down suddenly in the initial deposition, weak compaction, and postinfiltration states. This result suggests that, before it reaches a turning value, the matric suction has a limited effect on the interparticle force. However, the interparticle force reduces to zero when the matric suction is higher than this turning value. Here the turning values corresponding to the three states are $9.6 \mathrm{kPa}$, $32.7 \mathrm{kPa}$, and $128.1 \mathrm{kPa}$, respectively, which increase with the decrease of the particle distance. On the other hand, for the close arrangement state, the distance of the soil particles is the smallest among the four states. The interparticle forces at this state increase with the increase of matric suction continuously, which is significantly different from the former three states. In other words, the matric suction contributes significantly to the interparticle force for dense soil with a relatively low void ratio. However, regarding the loose state, the contribution of matric suction to the interparticle force is limited within a low suction range (e.g., $128.1 \mathrm{kPa}$ for the postinfiltration state).

During the drying process, the volume shrinkage occurs in both vertical and horizontal directions. The vertical shrinkage during drying induces subsidence that is different from the collapsibility, which occurs during wetting [14]. The interparticle force increases during the drying process. Therefore, it is the surface tension acting on the contractile skin and the matric suction that contribute to the interparticle force and further the formation of the vertical joints.

Furthermore, the tensile stress (i.e., interparticle force in macroscopic scale) is calculated. At first, the soil-water characteristic curve (SWCC) in the postinfiltration state is obtained using the tensiometer method. Typical suction measurement methods in the laboratory include the pressure plate method [30,31], filter paper method [32,33], and tensiometer method [34]. In this study, the TEN-15 tensiometer, which measures matric suction in the range of 0 to approximately $90 \mathrm{kPa}$, was used herein to obtain the drying soil-water characteristic curve of the sample. The sampling 


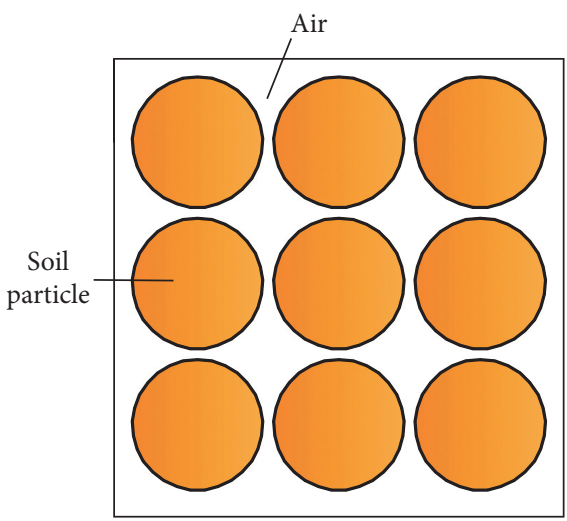

(a)

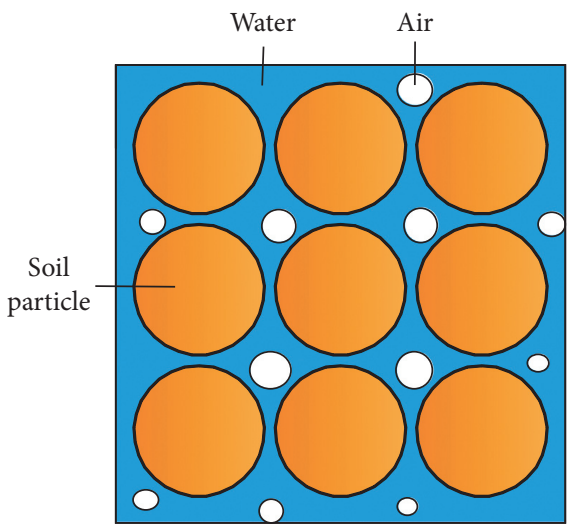

(c)

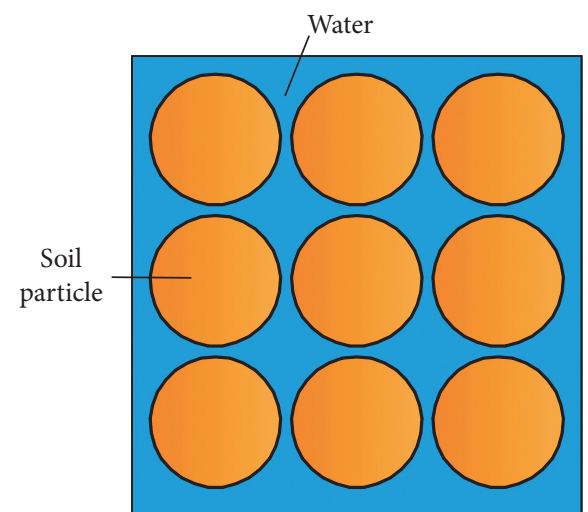

(b)

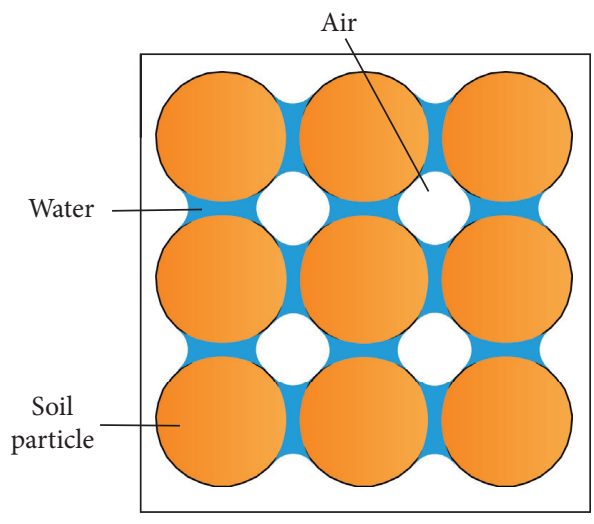

(d)

FIgURE 9: The process development of water-air-solid phases in loess: (a) totally dry state; (b) saturated state; (c) isolated air pore state; (d) water-air-solid interaction state.

TABle 3: The parameters in different experimental states.

\begin{tabular}{lccccc}
\hline Number & State of soil & Void ratio $e$ & Dry density $\rho_{d}\left(\mathrm{~g} / \mathrm{cm}^{3}\right)$ & Interparticle space $a_{c}(\mu \mathrm{m})$ & Shrinkage space $s(\mu \mathrm{m})$ \\
\hline 1 & Initial deposition & 1.650 & 1.02 & 16.84 & 1.74 \\
2 & Weak compaction & 1.360 & 1.14 & 16.20 & 1.10 \\
3 & Postinfiltration & 1.100 & 1.29 & 15.59 & 0.49 \\
4 & Dense arrangement & 0.910 & 1.42 & 15.10 & 0.00 \\
\hline
\end{tabular}

Note: shrinkage space $s$ is the difference between the interparticle space and $d_{50}$.

process was the same as the laboratory model experiment process. The measured data points were fitted by equation (13) [35]. The results are shown in Figure 11.

$$
w(\psi)=w_{r}+\frac{w_{s}-w_{r}}{\left\{1+\left[a\left(u_{a}-u_{w}\right)^{n}\right]\right\}^{m}},
$$

where $w$ is mass water content; $w_{r}$ and $w_{s}$ are residual water content and saturated water content, respectively; $u_{a}-u_{w}$ is matrix suction; $a, m$, and $n$ are fitting parameters.

According to Figure 6, assuming that the particle diameter is $15.1 \mu \mathrm{m}$ and the total length $l$ is $93.5 \mu \mathrm{m}$, there are 6 particles in both vertical and horizontal directions. The area of cross section is $S=(15.59 \times 6)^{2}=8750 \mu \mathrm{m}^{2}$. There are 36 connecting points, so the tensile stress $\sigma_{\mathrm{s}}$ is

$$
\begin{aligned}
\sigma_{s} & =\frac{n P_{s}}{S}=\frac{36 \times 10^{12}}{8750} \\
P_{s} & =4.11 \times 10^{9} P_{s} .
\end{aligned}
$$

In the previous equations, $n$ is the number of connecting points, $P_{s}$ is the interparticle force in every connection point, and $S$ is the area of the section. In this condition, parameters are calculated in the drying process. The data are presented in Table 4.

From the laboratory experiment, the water content is $31.5 \%$ when vertical joints appear. The tensile stress is $9.02 \mathrm{kPa}$ when matric suction increases to $17.5 \mathrm{kPa}$. This tensile stress is close to the largest interparticle force condition (i.e., interparticle force is $9.06 \mathrm{kPa}$ when matric 


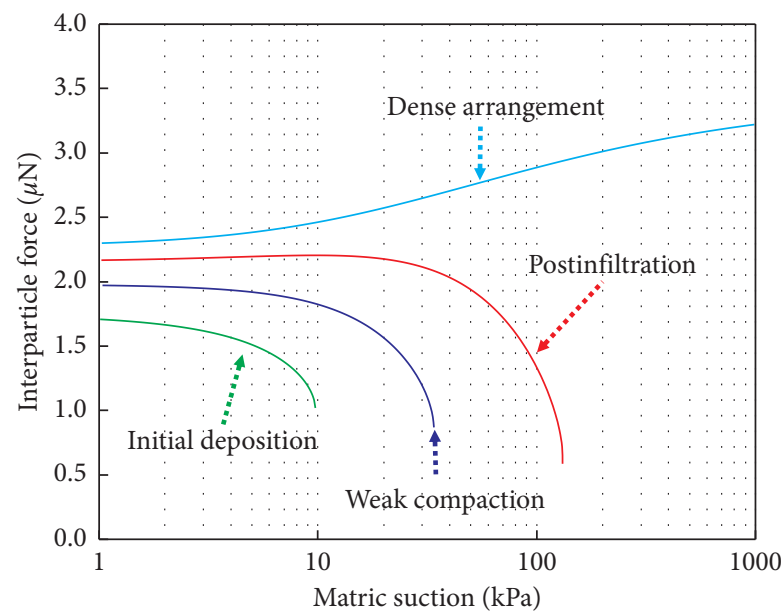

FIGURE 10: The change of interparticle force with matric suction in different states.

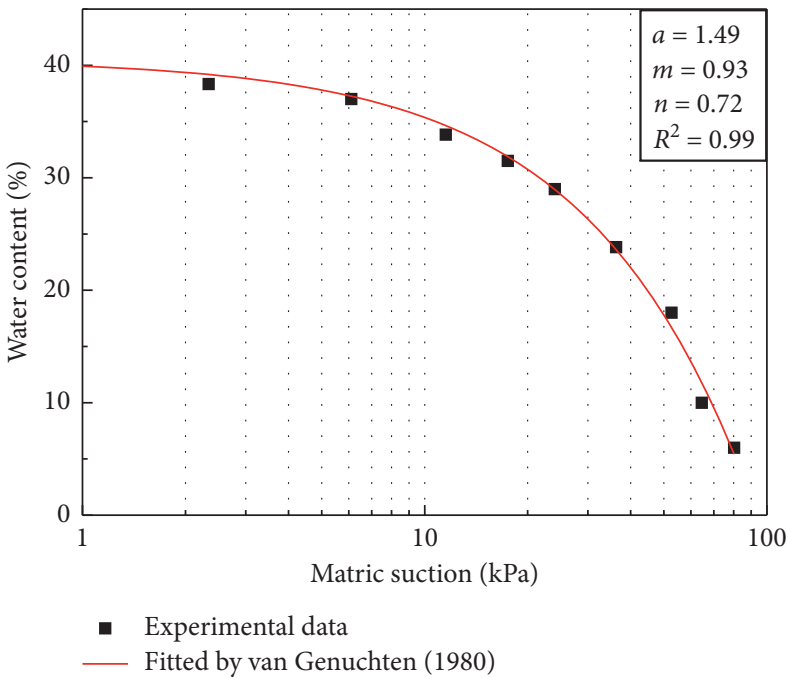

FIgURE 11: Soil-water characteristic curve.

TABLE 4: The parameters of interaction between soil particles at the $15.59 \mu \mathrm{m}$ interparticle spacing.

\begin{tabular}{lcccccc}
\hline Water content $w(\%)$ & $\begin{array}{c}\mathrm{t} u_{a}-u_{w} \\
(\mathrm{kPa})\end{array}$ & $\begin{array}{c}\text { Filling } \\
\text { angle } \Theta \\
\left({ }^{\circ}\right)\end{array}$ & $\begin{array}{c}\text { Shrinkable film } \\
\text { radius } r_{1}(\mu \mathrm{m})\end{array}$ & $\begin{array}{c}\text { Capillary } \\
\text { column radius } \\
r_{2}(\mu \mathrm{m})\end{array}$ & $\begin{array}{c}\text { Interparticle force } P_{s}\left(10^{6} \mathrm{~N}\right) \\
\text { Tensile stress } \sigma_{\mathrm{s}}(\mathrm{kPa})\end{array}$ \\
\hline 6.3 & 80.2 & 17.0 & 0.6 & 1.8 & 1.60 & 6.60 \\
9.9 & 64.5 & 19.7 & 0.7 & 2.1 & 1.79 & 7.36 \\
18.0 & 52.6 & 22.1 & 0.9 & 2.3 & 2.07 & 7.88 \\
23.8 & 36.2 & 26.4 & 1.2 & 2.7 & 2.16 & 8.52 \\
29.1 & 24.0 & 31.0 & 1.5 & 3.1 & 2.19 & 9.88 \\
31.5 & 17.5 & 34.2 & 1.9 & 3.4 & 2.21 & 9.08 \\
33.9 & 11.5 & 38.1 & 2.4 & 3.8 & 2.20 & 9.06 \\
37.2 & 6.1 & 42.8 & 3.1 & 4.1 & 2.19 & 9.00 \\
39.0 & 3.0 & 46.3 & 3.7 & 4.4 & 2.17 & 8.92 \\
40.6 & 1.0 & 49.1 & 4.4 & 4.6 & & \\
\hline
\end{tabular}

suction is $11.5 \mathrm{kPa}$ ). But, with continuing desaturation, the interparticle force in the microscope and tension stress in the macroscope decrease and the shrinkage stops. During the laboratory experiment, it was observed that joints did not develop during further drying. This phenomenon coincides with the theoretical calculation. The total shrinkage (the sum width of 9 vertical joints in Table 2) is $2.69 \mathrm{~cm}$. The theoretical estimation in the perimeter is $2.90 \mathrm{~cm}$ from the initial 
deposition state to the postinfiltration state, which is also similar to the experimental results.

\section{Discussion}

The available formation mechanisms of the loess vertical joint, which include the differential collapse deformation mechanism [23], tension stress concentration mechanism $[23,24]$, privilege pore characteristics [8], and biological activities [25], are all based on the nonuniform initial state. In other words, the initial state of the soil is anisotropic with more connected pores in the vertical direction. However, we deem that the aeolian loess is originally uniform. It is the wetting-drying circles which the soil experiences in the following decades that contribute to the anisotropy concentrated pores and vertical joints. This vertical joint (open or closed) will be inherited and develop furthermore at gravity loading during its depositional period. It can evolve into the process of densification or reerosion [20]. Unloading at the edge of slopes is a typical process to make the original crack extend to vertical joints with a length of several meters. Vertical joints in loess are deemed to inherit from the original crack.

This theoretical model is an ideal model without considering the fine clay particles clustering between the silt particles. In addition, this model attributes the deformation of the soil element to the variation of the distance between two soil particles without considering the rearrangement of the soil particles. Even though it simplifies the real condition of the soil, the theoretical model presented here provides an insight into the mechanical mechanism of vertical joints' formation. Based on the theory of unsaturated soil, both the matric suction and surface tension contribute to the interparticle force of soil particles. Besides, the contributions of the matric suction and surface tension are both related to the soil-water content (i.e., $r_{2}$ in the theoretical model). This is closely related to the test results. We need to note that the contribution of surface tension, which is always neglected in the literature [36-39], is highlighted in this study. This study enriches and perfects the research of loess vertical joints and provides scientific basis for prevention and control of geological disasters caused by vertical joint of loess.

\section{Conclusions}

The following conclusions can be drawn from the results presented in this paper:

(1) A laboratory model experiment was carried out to simulate the initial aeolian deposition process of the loess and the subsequent wetting-drying process that natural loess experiences after deposition. The basic parameters in initial deposition state, weak compaction state, and postinfiltration state were obtained, respectively. The generation, evolution, and cessation processes of cracks were well recorded.

(2) A theoretical model with unsaturated soil theory was proposed to calculate interparticle force or tensile force. This model explained the experimental phenomena well.

(3) The joints in loess can form in the initial deposition stage with a uniform particle arrangement. They occur when air-water-solid menisci emerge in the drying process after infiltration and stop evolving when the soil dries to a certain matric suction. Vertical joints in loess can be regarded as an inheritance of original cracks.

(4) The matric suction and surface tension stress arising from the solid-water-air contractile skin contribute to the formation of the loess vertical joints.

\section{Data Availability}

All data included in this study are available upon request by contacting the corresponding author.

\section{Conflicts of Interest}

The authors declare that there are no conflicts of interest regarding the publication of this paper.

\section{Acknowledgments}

This work was supported by the National Natural Science Foundation of China (nos. 41877242 and 41772278) and Major Projects of NSFC (no. 41790442).

\section{References}

[1] E. Derbyshire, "Geological hazards in loess terrain, with particular reference to the loess regions of China," EarthScience Reviews, vol. 54, no. 1-3, pp. 231-260, 2001.

[2] X. Hou, S. K. Vanapalli, and T. Li, "Water infiltration characteristics in loess associated with irrigation activities and its influence on the slope stability in Heifangtai loess highland, China," Engineering Geology, vol. 234, pp. 27-37, 2018.

[3] P. Li and S. J. Shao, "Can X-ray computed tomography (CT) be used to determine the pore-size distribution of intact loess?" Environmental Earth Sciences, vol. 79, no. 1, pp. 1-12, 2020.

[4] C. H. Juang, T. Dijkstra, J. Wasowski, and X. Meng, "Loess geohazards research in China: advances and challenges for mega engineering projects," Engineering Geology, vol. 251, pp. 1-10, 2019.

[5] J. Peng, P. Ma, Q. Wang et al., "Interaction between landsliding materials and the underlying erodible bed in a loess flowslide," Engineering Geology, vol. 234, pp. 38-49, 2018.

[6] B.-P. Wen and Y.-J. Yan, "Influence of structure on shear characteristics of the unsaturated loess in Lanzhou, China," Engineering Geology, vol. 168, pp. 46-58, 2014.

[7] D. Q. Tang, J. B. Peng, Q. Y. Wang, and J. S. Xu, "Lvliang typical loess landslide mechanism and characteristics," $A p$ plied Mechanics and Materials, vol. 90-93, no. 93, pp. 13131317, 2011.

[8] L. Feng, M. S. Zhang, W. Hu, Y. Dong, and X. J. Meng, "Discussion on microscopic, microcosmic characteristics and developmental mechanism of loess vertical joints," Rock and Soil Mechanics, vol. 40, no. 1, pp. 235-244, 2019, in Chinese. 
[9] G. Wang, T. Li, X. Xing, and Y. Zou, "Research on loess flowslides induced by rainfall in July 2013 in Yan'an, NW China," Environmental Earth Sciences, vol. 73, no. 12, pp. 7933-7944, 2015.

[10] L. Xu, F. C. Dai, Q. M. Gong, L. G. Tham, and H. Min, "Irrigation-induced loess flow failure in heifangtai platform, north-west China," Environmental Earth Sciences, vol. 66, no. 6, pp. 1707-1713, 2012.

[11] X. L. Xing, T. L. Li, and Y. K. Fu, "Determination of the related strength parameters of unsaturated loess with conventional triaxial test," Environmental Earth Sciences, vol. 75, no. 1, pp. 1-11, 2016.

[12] S. M. Haeri, A. Khosravi, A. A. Garakani, and S. Ghazizadeh, "Effect of soil structure and disturbance on the hydromechanical behavior of collapsible loessial soils," International Journal of Geomechanics, vol. 17, no. 1, pp. 1-15, 2016.

[13] C. L. Chen, D. F. Zhang, J. Zhang, and W. B. Zhang, "Research on the compression and wetting deformation behavior of intact loess under isotropic stress," Chinese Journal of Rock Mechanics and Engineering, vol. 36, no. 7, pp. 1736-1747, 2017, in Chinese.

[14] X. K. Hou, T. L. Li, S. K. Vanapalli, and Y. Xi, "Water percolation in a thick unsaturated loess layer considering the ground atmosphere interaction," Hydrological Processes, vol. 33, no. 5, pp. 794-802, 2019.

[15] P. Ma, J. Peng, Q. Wang, J. Zhuang, and F. Zhang, "The mechanisms of a loess landslide triggered by diversion-based irrigation: a case study of the South Jingyang Platform, China," Bulletin of Engineering Geology and the Environment, vol. 78, no. 7, pp. 4945-4963, 2019.

[16] L. Xu, F. C. Dai, L. G. Tham et al., "Field testing of irrigation effects on the stability of a cliff edge in loess, North-west China," Engineering Geology, vol. 120, no. 1-4, pp. 10-17, 2011.

[17] R. Q. Zeng, X. M. Meng, F. Y. Zhang et al., "Characterizing hydrological processes on loess slopes using electrical resistivity tomography - a case study of the Heifangtai Terrace, Northwest China," Journal of Hydrology, vol. 541, pp. 742753, 2016.

[18] T. L. Li, H. Wang, Y. K. Fu, and Y. Liang, "Test simulation on the forming mechanism of loess vertical joints," Journal of Earth Science and Environment, vol. 32, no. 6, pp. 127-134, 2014, in Chinese.

[19] D. Q. Tang, X. F. Yao, and J. B. Peng, "Loess joints development characteristics and space partition," Applied $\mathrm{Me}$ chanics and Materials, vol. 501-504, no. 504, pp. 312-317, 2014.

[20] Q. Z. Lu, J. B. Peng, Z. X. Chen, and X. A. Li, "Research on characteristics of cracks and fissures of loess and their distribution in loess plateau of China," Journal of Soil Water Conservation, vol. 19, no. 5, pp. 191-194, 2005, in Chinese.

[21] P. Sun, G. Wang, L. Z. Wu, O. Igwe, and E. Zhu, "Physical model experiments for shallow failure in rainfall-triggered loess slope, Northwest China," Bulletin of Engineering Geology and the Environment, vol. 78, no. 6, pp. 4363-4382, 2018.

[22] Y. Luo, T. H. Wang, and X. J. Liu, "Study on seepage character of loess vertical joint," Disaster Advances, vol. 6, no. 12, pp. 154-160, 2013.

[23] J. Luo, W. Xiang, Y. G. Wu, and Y. Wang, "Experimental study on formation of loess vertical joints in northern Shanxi Province," Journal of Yangtze River Scientific Research Institute, vol. 27, no. 3, pp. 38-41, 2010, in Chinese.

[24] Z. G. Wang and G. J. Kang, "The discussion on formation of loess vertical joints," Science in China, vol. 23, no. 7, pp. 765-770, 1993, in Chinese.
[25] B. F. Richthofen, "II.-On the mode of origin of the loess," Geological Magazine, vol. 9, no. 7, pp. 293-305, 1882.

[26] Y. Y. Wang, The Structural Characteristics and Physics Mechanical Properties of Loess in China, Science Press, Beijing, China, 1990, in Chinese.

[27] E. Derbyshire, R. Kemp, and X. Meng, "Variations in loess and palaeosol properties as indicators of palaeoclimatic gradients across the Loess Plateau of North China," Quaternary Science Reviews, vol. 14, no. 7-8, pp. 681-697, 1995.

[28] A. Assadi-Langroudi, S. Ng'ambi, and I. Smalley, "Loess as a collapsible soil: some basic particle packing aspects," Quaternary International, vol. 469, pp. 20-29, 2018.

[29] N. Lu and W. J. Likos, Unsaturated Soil Mechanics, Wiley, New York, NY, USA, 2004.

[30] A. Tarantino, D. Gallipoli, C. E. Augarde et al., "Benchmark of experimental techniques for measuring and controlling suction," Géotechnique, vol. 61, no. 4, pp. 303-312, 2011.

[31] C. W. W. Ng, H. Sadeghi, S. K. B. Hossen, C. F. Chiu, E. E. Alonso, and S. Baghbanrezvan, "Water retention and volumetric characteristics of intact and re-compacted loess," Canadian Geotechnical Journal, vol. 53, no. 8, pp. 1258-1269, 2016.

[32] J. A. Mũ̃ \pm oz-Castelblanco, J. M. Pereira, P. Delage, and Y. Cui, "The water retention properties of a natural unsaturated loess from northern France," GÃ@otechnique, vol. 62, no. 2, pp. 95-106, 2012.

[33] S. Rajesh and V. Khan, "Characterization of water sorption and retention behavior of partially saturated GCLs using vapor equilibrium and filter paper methods," Applied Clay Science, vol. 157, pp. 177-188, 2018.

[34] F. Sheng, H. Liu, K. Wang, R. Zhang, and Z. Tang, "Investigation into preferential flow in natural unsaturated soils with field multiple-tracer infiltration experiments and the active region model," Journal of Hydrology, vol. 508, pp. 137-146, 2014.

[35] M. T. V. Genuchten, "A closed-form equation for predicting the hydraulic conductivity of unsaturated soils," Soil Science Society of America Journal, vol. 44, no. 5, pp. 892-898, 1980.

[36] D. G. Fredlund, N. R. Morgenstern, and R. A. Widger, "The shear strength of unsaturated soils," Canadian Geotechnical Journal, vol. 15, no. 3, pp. 313-321, 1978.

[37] T.-H. Kim and C. Hwang, "Modeling of tensile strength on moist granular earth material at low water content," Engineering Geology, vol. 69, no. 3-4, pp. 233-244, 2003.

[38] N. Lu, T.-H. Kim, S. Sture, and W. J. Likos, “Tensile strength of unsaturated sand," Journal of Engineering Mechanics, vol. 135, no. 12, pp. 1410-1419, 2009.

[39] S. K. Vanapalli, D. G. Fredlund, D. E. Pufahl, and A. W. Clifton, "Model for the prediction of shear strength with respect to soil suction," Canadian Geotechnical Journal, vol. 33, no. 3, pp. 379-392, 1996. 